\title{
Solar Wear Tattoo - Combining Functional Materials Taking Advantage of Different UPF of Textiles, to Create Healthier Tattooing Alternatives
}

\author{
Vanessa Mendes ${ }^{1, a}$ and Mário Kong ${ }^{2}$ \\ ${ }^{1}$ PhD Candidate, Faculty of Architecture, University of Lisbon - FA-UL, 1349-055 Polo Universitário - Alto da Ajuda, \\ Lisboa, Portugal \\ ${ }^{2}$ PhD Architect, Professor Faculty of Architecture - University of Lisbon, Researchers and CIAUD-permanent member \\ of the Research Centre for Architecture, Urban Planning and Design FA-UL
}

\begin{abstract}
Tattooing process can be a painful experience whether achieving a permanent or temporary body art on skin, and there can be horrible consequences. By taking advantage of UV protection factor variables of fashion clothing materials, it is possible to create this kind of body art in a much healthier way. The material performance is key, besides UPF materials that relies on the material behaviour when combined, layer sequence of these materials used for the desired function is equally as important, if not, even more important so. When properly combined in the correct order, making use of the right technology it may be possible to test different combinations. The advantages are, besides creating a temporary tattoo, that the user can benefit from moderate sun bathing advantages, that can provide the desired body art design on skin and the sunbathing health benefits. All of this can only be possible with a deep understanding of the UV protection factor of fashion materials, and how it can be tested and used in the manufacturing process for the desired function.
\end{abstract}

\section{Body art - Tattooing process consequences}

By body art it is understood a wide range of physical and aesthetic interventions on the body, the usual daily routine includes body art interventions such as hair styling [1] and waxing for both genders. [2] Tattoos are a kind of body art that through time revealed to have certain social [3] and health implications that come across as unwanted consequences of having a tattoo, whether the tattoo is permanent or temporary. The health consequences all come down to the choice of the type of tattoo. [4] [5]

\subsection{Permanent tattooing process consequences}

There are different types of tattoos and all have different techniques when it comes to marking the body. [6] It is possible to qualify them in two fundamental categories: Temporary or permanent.

Within the permanent category, there are loads of styles that assume different aesthetics due to the methods applied in the process of making the body modification. [7] When it comes to permanent

\footnotetext{
${ }^{\mathrm{a} C}$ Corresponding author: vanessa.g.mendes@hotmail.com
} 
tattoos or scarification, the main consequence is the shin damage made in order to make the desired tattoo design. [8] Other consequences include: unwanted scares due to allergies or other skin diseases. Both consequences can result from different skin sensitivities which may vary from individual to individual. [5]

Fig. 1 shows a skin disorder due to unwanted consequences of making a permanent tattoo. This infection can, and most likely will, result in unexpected and unwanted scarification on skin. [5]

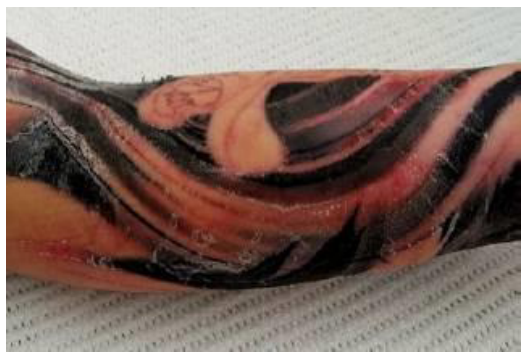

Figure 1. Staphylococci infection with swelling of the entire arm and constitutional symptoms.

\subsection{Temporary tattooing process consequences}

The temporary category is essentially the mehndi practice. Mehndi is the art of painting the body with a henna solution. [9] The risk of this practice, is when this solution contains artificial colouring chemicals that can create a permanent scar due to contact ulcers that appear on the skin, in case of an allergy outburst. [10]

Fig. 2 shows an unwanted consequence of making a supposedly temporary tattoo that, most likely, became permanent due to unexpected scarification of the skin. [11] This allergic contact dermatitis that can leave residual depigmentation for weeks or even scarification, can be caused by the addition of synthetic dyes like para-phenylenediamine (PPD), para-toluylenediamine or related chemicals.

These chemicals are used to darken the henna colour and shorten application times, despite the consequences caused by the black henna. [4]
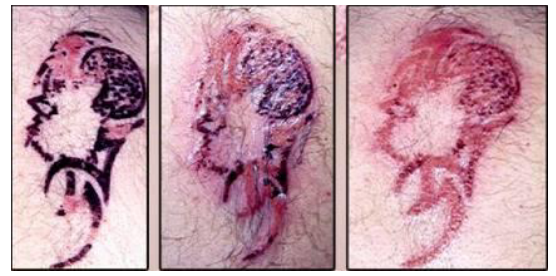

Figure 2. Example of skin contact ulcer due to skin allergy.

\section{UV protection factor in clothes for tattooing purposes}

Since every existing tattooing process can result in unwanted scars, a solution to this problem is to make use of an alleged 'textile disadvantage', to make tattooing through clothing possible. That will exclude the use of artificial pigments into making a tattoo, making use of the human body's natural pigment: melanin. [12]

Total UV protection textiles were made to provide total protection of the user's skin through clothes. These textiles were made because most textiles have different UV protection factors. These protection factors can change from textile to textile, depending essentially on composition [13] (including natural colour/ dying pigments), [14] [15] weave [16] and thickness of both yarn and finished textile. [17] Although UV protection factors in textiles can differ in less obvious ways by adding finishings to the textile, in order to enhance its UPF properties. [18] On the contrary, other 
textiles finishings such as mercerizing and canotizing, to make a fluorescent glow on the textile, can decrease its UPF properties. [19]

The more the body is covered up with high UPF textiles, the better the body will be protected from the sun. The burkini is a perfect example of 50+ UPF beachwear, [20] although high UPF factors are a main concern in everyday casual clothing. [21] These 2 examples imply that textiles with low UPF are a disadvantage.

Taking this information in to consideration, if different textiles and fashion materials with different UV protection factors are combined, it is possible to create contrasting two colour solar tattoos, making use of fashion materials and natural resources: Clothes and sun exposure. [22] Tanning beds are an alternative to sun exposure, as long as regulations are followed to guarantee the users health safety. The user in this case should also be informed that tanning beds are for tanning purposes only, [23] since just some tanning beds can provide vitamin D, not always being the case. [24]

\subsection{Examples of varies of UV protection factors in textiles and how they can be used}

\subsubsection{The UV protection factors in textiles}

Different textiles can have different UV protection factors according to their interaction with light. Taking in to consideration the material characteristics, they have different results when it comes to light interaction. It all comes down to reflection, absorption and transmission of the light. [25]

Table 1. Examples of textiles with different UV protection factors.

\begin{tabular}{|c|c|c|}
\hline Sample details & UPF Rating & UV protection category \\
\hline White Woven cotton & $5+$ & Not relatable \\
\hline White nylon knit & $10+$ & Moderate \\
\hline White polyester woven & $15+$ & Moderate \\
\hline White cotton knit & $30+$ & Very high \\
\hline White woven polyester crepe & $50+$ & Maximum \\
\hline Cream woven wool & $50+$ & Maximum \\
\hline
\end{tabular}

The upper half of table 1 shows textiles that can be used to tan, since their protection factors range from low $5+$ to moderate $15+$.

The lower half of the same table shows textiles that can be used to block UVs, since their protection factors range from very high $30+$ to maximum $50+$. [26]

\subsubsection{How they can be used}

The essential rule to be applied, in order to achieve a solar tattoo through the use of fashion materials, is that the textiles and materials of the main area of the beachwear differ from the textiles and materials used on the tattooing area.

This is a product meant for the user. The fashion user has a need for multiple choices in order to satisfy its taste. [27] Changing materials variables is a delicate procedure, so dermatological tests may become required in order to ensure the users comfort, health and safety.

Meaning that comfort can affect the user when it comes to aesthetics but as well as the touch of the materials. [28] These materials need to be selected carefully and perhaps, may be in need of dermatological tests, in order to avoid complications that can create contact dermatitis. Allergic contact dermatitis can occur due to numerous chemicals that may be incorporated into the textiles and 
clothing during the processes form fibre formation, spinning, fabric construction to dyeing and finishing. [29]

\subsection{Tattooing with fashion clothing materials - advantages and benefits}

Sun exposure/ artificial UV exposure can result in several problems [30] but, it is proven that regular mild sun exposure can improve health and avoid physical issues related to vitamin D deficiency. [31]

\subsubsection{Advantages/ benefits of creating tattoos with clothing materials}

Sun exposure on a daily basis is, in fact, vital to a healthy body functioning. The clothing material area that allows the sun radiation to tan the users skin, will allow its body to receive the benefits that sun exposure can provide.

As well as the other area of the clothing that blocks the UV radiation on the user's skin, will benefit from the anti-ageing of the skin that is provided in the absence of sun exposure. [32]

It is up to the user to choose its beachwear model according to the desired tattoo design, and consequentially, the benefits he wants the most, considering his model of choice, that can block most of the UV rays from the skin, making a tattoo area based on melanin stimulation, or, allowing most of the UV rays on the skin, making a tattoo area based on melanin stimuli restriction.

\section{Healthier body art tattoo - How it works}

The textiles characteristics mentioned can be combined to create an efficient and healthy tattoo, with all the benefits of sun exposure. The key is to put these materials in the right places meaning that, if the desire is to make a positive tattoo, materials that are UV receptive are used in the tattoo area and to make a negative tattoo, materials that block UV are used in the tattoo area.

\subsection{Previous tests results}

Previous tests were made with textiles, providing the information that different materials with different material behaviours can, create contrasting results on skin, using various fashion materials with different UPF. The materials used were 2 knitted textiles made of polyamide, with different structures but, similar in colour and thickness. Additional fashion adornments were added as well.

Material overlap on its own is enough to create a possible mark on skin, due to the amplified thickness. So, in order to remove the possibility of unwanted marks on skin, seam overlay can be hidden in the material overlap area of UV blockage. (Figure 3) [22]

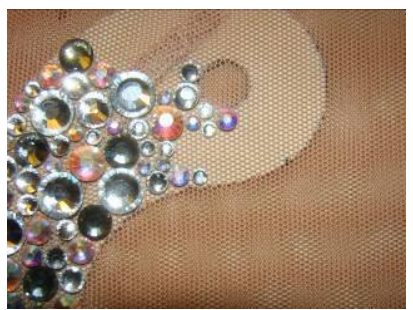

Figure 3. Materials and finishings overlay with the seam in between - Authors photograph.

Despite the overlap used, it is not essential for the UV blockage since this blockage works on its own without the seam overlay, it is only an aesthetic improvement to avoid unwanted sun marks due to bad pattern making, that can expose a seam textile overlay to UV, making it possible to appear an unwanted tan mark on the user's skin as a consequence (Figure 4) [22] 


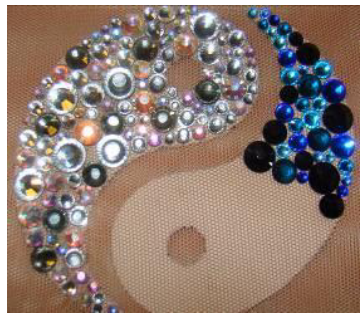

Figure 4. Materials and finishings overlay without the seam in between. - Authors photograph

In a popular sense, the user tends to call a bad tan line to an anaesthetic lace silhouette on skin, as a result of bad beachwear design. [33] In this sense, an exposed seaming overlay in low SPF textiles could be called as bad beachwear design, and should be avoided by hiding it in the materials and finishings overlap.

Alternative to this manufacturing process, it's to use fabric/ outfit made in a circular loom. A process that is usually used to make socks without seams. [34] This way, eliminating the sewing area, there is no need to hide or incorporate it in the UV blockage area, in order to prevent the so called bad tan line. This manufacturing process should be included in future prototypes. In this case, extra care with the knitwear should be taken, due to the knitwear behaviour.

Knitted structured fabrics stretch capacity, is part of the physical behaviour of its knit loops. [35] Material overlap is key to improve UPF in the tattooing area, increasing thickness and raising UPF. The strategical overlap of these materials creates a stronger UV barrier. Plus, the overlap of the materials used, restrains the natural stretching of the knitted fabric structures. (Figure 5)

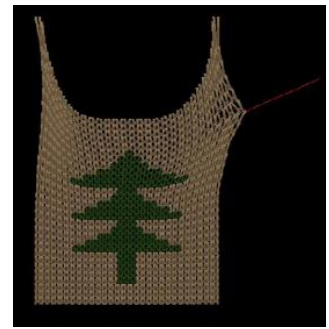

Figure 5. Physical behaviour of knitwear. [35]

Restraining the knit loops natural behaviour, prevents the tattoo area distortion. [22] The restrain area can go in the tattoo, to make a negative tattoo (Figure 6) or, in the area that surrounds the positive tattoo, to prevent the distortion of the positive tattoo area. Further research is needed in order to draw conclusions for the positive solar tattoo.

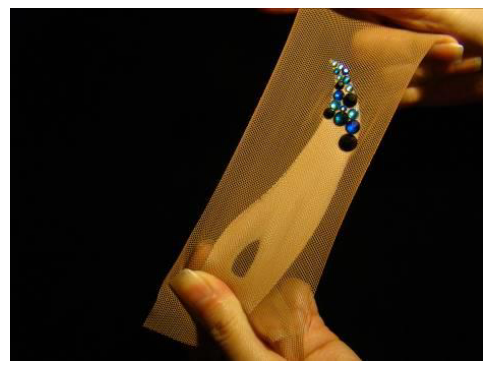

Figure 6. Knitted loops restrain. - Authors photograph.

\subsection{Other materials and techniques - Same logic}


The same logic can be applied with different materials, that can lead to similar results. The goal is to always create a contrasting skin colour through melanin stimuli, making use of fashion materials with different UPF. The manufacture can also suffer changes. These changes can be applied specially to the sequence in which materials and finishings are overlapping and firming up together, from the inner layers that come in contact with the user's skin, to the outer layers that are exposed to external elements.
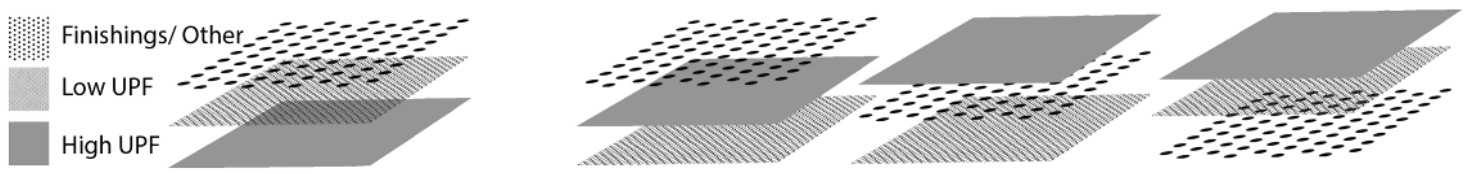

Figure 7. Materials and finishings overlay sequences diagrams with labels.

In Fig. 7, the bottom section represents the materials or finishings that come into contact with the user's skin. The upper section of the same figure (Figure 7) represents the materials or finishings of the outer layer that stay on the surface, on the show, and can be directly observed while the user is wearing a finished outfit/ accessory made according to the respective material overlay sequence.

On the far left, materials and finishings overlay sequence used in the previous test.

On the right, examples of materials and finishings overlay sequences to be tested in the present ongoing research. Materials and finishings overlay sequences, other than the ones that are exemplified above, may be tested as well.

The outer layers need extra attention when it comes to materials resistance to natural degradable factors, since UV exposure, of both artificial light of tanning beds and natural sun light, can damage the textiles properties. [13]

Other textile damaging agents can be found in places that user may go to tan his skin. Swimming pool water contains chlorine which affects the textiles durability with repeated exposure. [36]

Whatever the materials and finishings overlay sequences chosen, it is expected a solar tattoo to appear on skin, due to contrast between melanin stimuli and UV blockage.

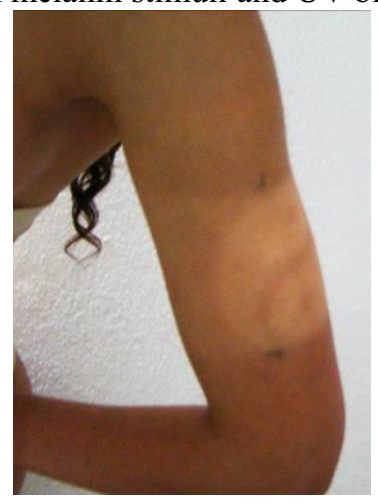

Figure 8. Negative solar tattoo on skin, making use of the previous test prototype - Authors photograph [22]

The temporary tattoo obtained through sun exposure, (Figure 8) is an example of the desired results of contrast on skin.

Other prototypes made with other materials, finishings and overlay sequences, will be tested with the goal of creating a contrasting drawing in the body. This contrast can be achieved like this, by creating a tattoo area in negative with melanin stimuli restriction, or the other way around, allowing to $\tan$ in the drawing area, making a positive tattoo, blocking the UV rays in the rest of the prototype.

No quantitative data was registered in this prototype's first test. Tests may need to be repeated in order to retrieve precise information about UPF of these materials, in order to be able to compare the results with the future prototypes to be made and tested as well. 


\section{Conclusions}

Spectrometers (and other accessories) are essential tools to calculate the spectral region, measuring the UV transmission in fabrics. [26]

Further research is needed to fully understand the limits of the range of materials that can be combined, and their orders of overlap sequences respectively. Samples should be made and tested by measuring the UV transmission with the necessary equipment, to obtain quantitative results with precision.

Test results can be compared, so that full understand the potential of each sample can be achieved. Only then it is possible to decide which sample is the most effective for the desired result. Creating a high contrast on the skin, due to samples that combine textiles with different UPF.

The main reason to make different multiple tests, besides obtaining effectiveness results, testing the limits of material combinations that allow for this solar tattoo through textiles, opens up to new possibilities, which is important in order to satisfy the users need of choice.

This practical experiment can be achieved through the application of a quantitative experimental methodology, with a qualitative research basis on the users taste, [37] to expand the technological possibilities of the present ongoing research.

\section{References}

1. T. Nicolas, Body art, 126 (Thames \& Hudson, London, 2014)

2. A. Smelik, Cri. Stu. Fash. Bea., A close shave: The taboo on female body hair, 2, 240 (2015)

3. M. Miflin, Bodys of subversion, 134, 136 (powerhouse books, Brooklyn, New York, 2013)

4. A. Hazra, Ind. Jou. Psic. XXXIV Annual conference of the Indian pharmacological society, Adverse reactions to henna, 34, 436 (2002)

5. J. Serup, J. T. Linnet, O. Olsen, N. Harrit, B. Møhl, H. Westh, The council on health and disease prevention, Tattoos - Health, risks and culture 70, 87 (2015)

6. E. Schildkrout, Ant. Win., Body art as visual language, 2, 3, 4 (2001)

7. S. M. Abbasi, Ind. J. Res. Par., Body adornment and modification: Is it art or is it torture, 2, 1, 2 (2013)

8. R. Lemay, The tattoo artist's black book, 36 (2008)

9. C. Fabius, Mehndi: The art of henna painting (Harmony, 1998)

10. S. Benomar, L. Ismaili, M. Rmili, L. Benzekri, B.; Hassam, Revue Française d'Allergologie, Tatouage au henné noir: au-delá de l'eczéma de contact, 49, 376-3778 (Elsevier B. V., 2009)

11. C. Cartwright-Jones, Henna is not black (2003)

12. F. Hu, J. Soc. Cosm. Chem., Melanocytes and melanin pigmentation, 19, 565-580 (1968)

13. D. Saravan, AUTEX Res. J., UV protection textile materials, 7, 56 (2007)

14. S. Venkatakrishnan, P. K. Mandhyan, R. Narkar, M. K. Kumar, Ind. J. App. Res., Studies on the physical properties of naturally coloured cotton \& development of eco-friendly UV protected fabric, 5, 643 (2015)

15. A. A. Salman, Z. M. Abdel-Megied, N. El-Mohsen, Seddik K. M., M. El-Aziz, Int. J. Sci. Res., Textiles \& apparel as UV protectives in medical applications, 4, 2302 (2015)

16. A. M. Grancarić, Ž. Penava, A. Tarbuk, VI Symposium contemporary technologies and economic development, UV protection of cotton - The influence of weaving structure, 230 (2005)

17. P. D. Dubrovski, Woven fabrics and ultraviolet protection, 284 (Intech, Croatia, 2010)

18. A. Ghani, W. Qorshi, A. Romyia, R. El-Sayd, Int. Des. J., Treatment of children's garments natural fabrics for protection against ultraviolet radiation, 4, 104 (2010)

19. A. M. Grancarić, T. Pušić, A. Tarbuk, I Jančijev, Int. Col. Ass., Interim Meeting of the International Color Association, The fluorescence of sunprotected white cotton fabrics, 126 (2004)

20. K. Dabrowska, The burkini: A muslim sportswomens' dream come true, 29 (Islamic Tourism, 2007) 
21. P. Hulme, Fabrics China ${ }^{\circledR}$ Hangtag Program Gains Momentum, 5 (Textile connection, Singapore, 2014)

22. V. Mendes, Solar Wear Tattoo (Faculty of Architecture, Lisbon, 2015)

23. H. W. Lim et al, J. Am. Acad. Dermatol., Sunlight, tanning booths and vitamin D, 52, 871-872 (2009)

24. S. Balk, D. Fisher, A. Geller, M. Weinstock, Evaluation of indoor tanning health claims (State Office of the Attorney General, New York, 2015)

25. H. Yang, S. Zhu, N. Pan, J. App. Pol. Sci., Studying the mechanisms of titanium dioxide as ultraviolet-blocking additive for films and fabrics by an improved scheme, 92, 3202 (2003)

26. Z. Bilimis, Measuring the UV protection factor (UPF) of fabrics and clothing (Agilent technologies, Mulgrave, Australia, 2011)

27. G. Moore, Promoção de moda, 20 (Editorial Gustavo Gili, Barcelona,2013)

28. S. Bragança, L. Fontes, P. Azeres, E. R. Edelman, M. Carvalho, $6^{\text {th }}$ international conference on applied human factors and ergonomics, The impact of work clothing design on workers' comfort, 3, 5890 (Elsevier B. V., 2015)

29. W. Zhong, Cutaneous and ocular toxicology, Textiles and human skin, microclimate, cutaneous reactions: An overview, 25, 25 (Taylor \& Francis, 2006)

30. J. D'Orazio, S. Jarrett, A. Amaro-Ortiz, T. Scott, Int. J. Mol. Sci., UV radiation and the skin, 14, 12226, 12227 (2013)

31. T. C. Chen, Z. Lu, M. F. Holic, Photobiology of vitamin D, 36, 37 (Humana press, 2010)

32. M. Ichihashi, H. Ando, M. Yoshida, Y. Niki, M. Matsui, Anti-Ageing Medicine, Photoageing of the skin, 6, 53, 54 (Japanese Society of Anti-Ageing Medicine, 2009)

33. T. E. Morissei, The strappy swimsuit trend creates the world's worst tan lines (2016) [ http://jezebel.com/the-strappy-swimsuit-trend-creates-the-worlds-worst-tan-1585463004]

34. M. Araújo, E. M. M. Castro, Manual de engenheiria textil (Calouste Gulbenkian Foundation, Lisbon, 1986).

35. F. Durupinar, U. Güdükbay, Computer \& Graphics, Procedural visualization of knitwear and woven cloth, 31, 781 (Elsevier B. V., 2007)

36. K. M. Borchard, California state science fair, Polyester vs. Nylon: Which material is best for swimsuits? (2006)

37. L. Pardal, E. S. Lopes, Métodos e técnicas de investigação social, 20, 21 (Areal Editores, Porto, 2011) 